\title{
Oryeongsan suppressed high glucose-induced mesangial fibrosis
}

\author{
Jung Joo Yoon ${ }^{1,2}$, Yun Jung Lee ${ }^{1,2}$, So Min Lee ${ }^{1,2}$, Dae Gill Kang ${ }^{1,2,3^{*}}$ and Ho Sub Lee ${\text { L, } 2,3^{*}}^{\circ}$
}

\begin{abstract}
Background: The pathological change of kidney in diabetic nephropathy is represented hypertrophy, inflammation, and renal fibrosis. Oryeongsan, traditional oriental herbal formula, is widely used for the treatment of nephrosis, dropsy, and uremia. This study was examined whether Oryeongsan attenuate high-glucose (HG)-promoted rat mesangial cell fibrosis and matrix accumulation, major features of diabetic glomerulosclerosis.

Methods: Oryeongsan was mixed traditional herbal medicine, Alisma orientale Juz, Polyporus umbellatus Fries, Atractylodes macrocephala Koidez, Poria cocos Wolf and Cinnamomum Cassia Presl (5:3:3:1). Renoprotective role in diabetic nephropathy of Oryeongsan was evaluated by $\left[{ }^{3} \mathrm{H}\right]$-thymidine incorporation, Western blot, RT-qPCR and immunofluorescence microscopy assay.

Results: Rat mesangial cell proliferation induced by HG was significantly accelerated, which was inhibited by Oryeongsan in a dose dependent manner. HG enhanced expression of fibrosis biomarkers such as collagen IV and connective tissue growth factor (CTGF), which was markedly attenuated by Oryeongsan. Oryeongsan increased HG-inhibited membrane type-1 matrix metalloproteinase expression (MT1-MMP) and MMP-2 promotor activity, whereas suppressed HG-induced tissue inhibitor of matrix metalloproteinase-2 (TIMP-2) expression. Moreover, Oryeongsan promoted extracellular matrix degradation through disturbing transforming growth factor $\beta$ (TGF- $\beta$ )-Smad signaling. This study further revealed that Oryeongsan ameliorated HG-induced mesangial inflammation accompanying induction of intracellular cell adhesion molecule-1 (ICAM-1) and monocyte chemoattractant protein-1 (MCP-1). Moreover, pretreatment of Oryeongsan inhibited NF-KB translocation in HG-exposed mesangial cell.
\end{abstract}

Conclusion: These results demonstrate that Oryeongsan has protective effect against renal proliferation, fibrosis, and inflammation. Therefore Oryeongsan may be specific therapies targeting renal dysfunction leading to diabetic nephropathy.

Keywords: Oryeongsan, Mesangial cell, Proliferation, Fibrosis

\section{Background}

Diabetic nephropathy is characterized by aberrant alterations such as extracellular matrix (ECM) accumulation ultimately leading to chronic renal failure. The pathological changes of diabetic nephropathy include kidney hypertrophy, glomerulus and tubular basement membrane thickening, tubular interstitial fibrosis and arteriosclerosis.

\footnotetext{
* Correspondence: dgkang@wku.ac.kr; host@wku.ac.kr

'Professional Graduate School of Oriental Medicine and College of Oriental Medicine, Wonkwang University, Shinyong-dong, Iksan, Jeonbuk 570-749,

Republic of Korea

${ }^{2}$ Hanbang Body-fluid Research Center, Wonkwang University, Shinyong-dong, Iksan, Jeonbuk 570-749, Republic of Korea

Full list of author information is available at the end of the article
}

Increased mesangial cell proliferation is one of the major pathologic features in the early stage of diabetic nephropathy [1]. Knowledge of the role of rat mesangial cells in normal glomeruli and of their response to pathological stimuli is crucial to the understanding of these disease processes [2]. There are few data on the effects of pharmacological intervention on mesangial cell proliferation in diabetic nephropathy.

The first and most distinctive glomerular lesion of diabetes is mesangial expansion concurrently accompanying mesangial hyperplasia, which precedes interstitial disease called diabetic glomerulosclerosis [3]. Mesangial cells, which are contractile, smooth muscle-like cells located in the intercapillary space of the glomerular tufts, are thought to

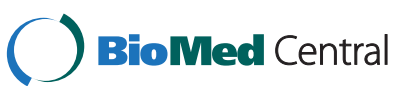

(c) 2015 Yoon et al.; licensee BioMed Central. This is an Open Access article distributed under the terms of the Creative Commons Attribution License (http://creativecommons.org/licenses/by/4.0), which permits unrestricted use, distribution, and reproduction in any medium, provided the original work is properly credited. The Creative Commons Public Domain Dedication waiver (http://creativecommons.org/publicdomain/zero/1.0/) applies to the data made available in this article, unless otherwise stated. 
be the primary producers of mesangial ECM constituents. The mesangial matrix is normally composed of various macromolecules, including fibronectin, laminin, collagen, and thrombospondin, as well as various proteoglycans [4]. Mesangial cells are thought to play an important role in the metabolism of type IV collagen controlling its synthesis and degradation, increased synthesis or decreased degradation of type IV collagen by mesangial cells could result in the expansion of ECM, leading to mesangial lesion expansion [5].

CTGF may contribute to diabetic renal disease not only by induction of ECM synthesis but also through inhibition of matrix degradation. HG caused a decrease in ECM degradation by mesangial cells, and in glomeruli [6]. This lesser degradation has been shown to occur through changes in the balance of the family of metal ion-dependent enzymes known as the matrix metalloproteinases (MMPs) and their specific inhibitors, the tissue inhibitors of MMPs (TIMPs), in particular, TIMP-1. We have recently shown that CTGF mediates the effects of HG to inhibit human renal mesangial cell matrix degradation through the up-regulation of TIMP-1 by CTGF [7].

TGF- $\beta 1$ is thought to play an important role in mediating the hypertrophic and fibrotic/sclerotic manifestations of diabetic nephropathy [8]. Previous studies have provided evidence that TGF- $\beta 1$ mediates the accumulation of ECM molecules in mesangial cells and tubular cells [9]. Inhibition of TGF- $\beta 1$ significantly reduced renal fibrosis and decreased the mRNA levels of key mediators of ECM deposition in the kidneys of $\mathrm{db} / \mathrm{db}$ mouse [10]. Thereby, induction and activation of the TGF- $\beta /$ Smad signaling cascade is critical for the initiation of fibrogenic cell responses. Subsequently, ligand binding causes a recruitment and phosphorylation of receptor-Smads (R-Smads), namely Smad-2, and Smad-3 proteins [11]. These activated R-Smads heterodimerize with the Co-Smad, mainly Smad-4, to build up a transcriptionally active complex which translocates to the nucleus where it modulates the expression of TGF- $\beta$ target genes [12].

Recently, it is believed that diabetic nephropathy is one kind of chronic inflammation [13]. Growing evidences demonstrated that activation of nuclear factor-kappa B $(\mathrm{NF}-\mathrm{kB})$ and subsequently coordinated expression of gene products may play an important role in the pathogenesis of diabetic nephropathy [14]. Mononuclear macrophage infiltration and abnormal expression of inflammatory mediators including intercellular adhesion molecule-1 (ICAM-1), MCP-1, TGF- $\beta 1$, can be observed in nephridial tissue in the early stages of diabetic nephropathy [15]. In diabetic setting, the activated NF- $\mathrm{kB}$ translocates into the nucleus and triggers the expression of its target genes including ICAM-1, MCP-1, and TGF- $\beta 1$ which in turn induce persistent and enhanced inflammation, and finally lead to excessive fibronectin (FN) production and ECM accumulation resulting in acceleration of the pathogenesis of glomerular sclerosis and tubulointerstitial fibrosis [16].

Oryeongsan (known as Wulingsan in China) is a wellknown blended traditional herbal medicine, comprising 5 herbs, Alisma orientale (Sam.) Juz. (Alismataceae), Polyporus umbellatus Fries (Polyporaceae), Atractylodes macrocephala Koidez (Compositae), Poria cocos Wolf (Polyporaceae) and Cinnamomum Cassia Presl (Laruaceae). It was originally recorded in an ancient Chinese medicine book "Treatise on Febrile Diseases" (Shanghan Lun or Shanghan Zabing Lun in Chinese) and has been reported to possess renal protective effects from renal diseases such as diabetes induced renal damage [17], and adriamycininduced nephrotic syndrome [18] in experimental models.

An important question is whether Oryeongsan would have an effect on HG-induced mesangial cell fibrogenesis. Therefore, the present study was performed to determine the possible effects of a crude water extract of Oryeongsan on proliferative, inflammatory and fibrogenic phenotypic changes of primary rat mesangial cells induced by HG.

\section{Methods}

\section{Preparation of a water extract from Oryeongsan}

Herbarium voucher specimen of Oryeongsan (No. HBH112) was kindly provided from Korea Institute of Oriental Medicine, Daejeon, South Korea. Formula of Oryeongsan, Alisma orientale (Sam.) Juz. (Alismataceae), Polyporus umbellatus Fries (Polyporaceae), Atractylodes macrocephala Koidez (Compositae), Poria cocos Wolf (Polyporaceae) and Cinnamomum Cassia Presl (Laruaceae) were mixed according to the ratio of 5:3:3:3:1 in weight respectively and ground into a crude powder. Oryeongsan $(281 \mathrm{~g})$ was boiled with $2 \mathrm{~L}$ of distilled water at $100^{\circ} \mathrm{C}$ for $2 \mathrm{~h}$. The extract was filtered through Whatman No. 3 filter paper and centrifuged at $990 \times \mathrm{g}$ for $20 \mathrm{~min}$ at $4^{\circ} \mathrm{C}$. Supernatant was concentrated using a rotary evaporator and then the resulting extract $(65.67 \mathrm{~g})$ was lyophilized using a freeze-drier and retained at $-70^{\circ} \mathrm{C}$ until required.

\section{Mesangial cell cultures}

All experimental procedures were carried out in accordance with the National Institute of Health Guide for the Care and Use of Laboratory Animals and were approved by the Institutional Animal Care and Utilization Committee for Medical Science of Wonkwang University (No. WKU12-14). Rat mesangial cells were isolated and cultured by modifying a standard collagenase digestion method as previously described [19]. Briefly, male Sprague-Dawley (SD) rats weighing 150-175 g were anesthetized and their kidneys removed. Renal cortical tissues were separated from the medulla and minced in D-Hank's balanced buffer using sterile conditions. Minced renal cortical tissues were filtered through 
220, 100, and then $76 \mathrm{~mm}$ stainless steel mesh filters and subsequently digested in $0.1 \%$ collagenase (type IV) solution at $37^{\circ} \mathrm{C}$ for $30 \mathrm{~min}$. After centrifuging at $1,000 \mathrm{rpm} / \mathrm{min}$ for $10 \mathrm{~min}$ at room temperature, pellets were re-suspended with $5.4 \mathrm{mmol} / \mathrm{L}$ glucose DMEM supplemented with $15 \% \mathrm{FBS}, 100 \mathrm{U} / \mathrm{mL}$ penicillin, $100 \mathrm{mg} / \mathrm{ml}$ streptomycin, and $5 \mathrm{mg} / \mathrm{ml}$ bovine insulin. The dispersed glomeruli were placed in $100 \mathrm{~mm}$ plastic dishes with the same culture medium and incubated in a humidified incubator at $37^{\circ} \mathrm{C}$ under $95 \%$ air and $5 \% \mathrm{CO}_{2}$. The culture medium was changed every 3 days. Cell outgrowth from glomeruli was observed every 2-3 days after seeding, which would reach confluence after 30 days. The cells from passages 5-10 were employed in the current study. In some experiments, the TGF- $\beta$ type I receptor inhibitor SB431542 (Sigma, $10 \mu \mathrm{M}$ ) was used to test TGF- $\beta$ type I -independent mesangial fibrosis and inflammation.

\section{Assessment of cell number}

Rat mesangial cells were plated in culture flasks and incubated with indicated concentrations of Oryeongsan (from $0,1,10$, and $50 \mu \mathrm{g} / \mathrm{mL}$ ) with or without HG $(25 \mathrm{mM})$ for $24 \mathrm{~h}$. The cells were removed by treatment of trypsine/EDTA solution and collected by centrifugation. Resuspend the cell pellet in $1 \mathrm{ml}$ medium, moved in different tube to resuspension of $10 \mu \mathrm{l}$ and then mixed with $0.4 \%$ trypan blue. The mixture of $10 \mu \mathrm{l}$ was added to the chamber ports on one side of the Countess $^{\text {Tw }}$ cell counting chamber slide according to Invitrogen Corporation's recommended protocol using a Countess $^{\mathrm{Tm}}$ Automated Cell Counter (Invitrogen Corporation, Van Allen Way, Carlsbad, CA).

\section{Measurement of cell proliferation}

$\left[{ }^{3} \mathrm{H}\right]$-thymidine incorporation was measured to determine the effect on rat mesnagial cell proliferation. Quiescent cells were treated with $25 \mathrm{mM}$ glucose and Oryeongsan, respectively, and $1 \mu \mathrm{Ci}$ of $\left[{ }^{3} \mathrm{H}\right]$-thymidine was added (methyl- $\left[{ }^{3} \mathrm{H}\right]$ thymidine $50 \mathrm{Ci} / \mathrm{mmol}$; Amersham, Oakville, Ontario, Canada). After incubation for $24 \mathrm{~h}$, cells were washed once with $2 \mathrm{ml}$ of ice-cold PBS for 10 minutes, extracted three times with $2 \mathrm{ml}$ of cold $10 \%$ TCA for 5 minutes each time, and solubilized for at least 30 minutes at room temperature in $0.2 \mathrm{ml} 0.3 \mathrm{~N}$ $\mathrm{NaOH}, 1 \%$ SDS. After neutralizing with $0.2 \mathrm{ml} 0.3 \mathrm{~N} \mathrm{HCI}$, $\left[{ }^{3} \mathrm{H}\right]$-thymidine activity was measured in a liquid scintillation counter (Beckman LS 7500, Fullerton, CA). Each experiment was performed in triplicate or quadruplicate.

\section{Western blot analysis}

Cell homogenates ( $40 \mu \mathrm{g}$ of protein) were separated on $10 \%$ SDS-polyacrylamide gel electrophoresis and transferred to nitrocellulose paper. Blots were then washed with $\mathrm{H}_{2} \mathrm{O}$, blocked with $5 \%$ skimmed milk powder in TBST
[10 mM Tris- $\mathrm{HCl}$ (pH 7.6), $150 \mathrm{mM} \mathrm{NaCl}, 0.05 \%$ Tween-20] for $1 \mathrm{~h}$ and incubated with the appropriate primary antibody at dilutions recommended by the supplier. Then the membrane was washed, and primary antibodies were detected with goat anti-rabbit-IgG conjugated to horseradish peroxidase, and the bands were visualized with enhanced chemiluminescence (Amersham, Buckinghamshire, UK). Protein expression levels were determined by analyzing the signals captured on the nitrocellulose membranes using the Chemi-doc image analyzer (Bio-Rad, Hercules, CA).

\section{RNA isolation and real-time qRT-PCR}

A kit from Qiagene (RNeasy ${ }^{\text {Ta }}$ Plus mini kit) was used for RNA isolation from cell cultures, and RNA quality was tested by measuring the ratio $260 / 280 \mathrm{~nm}$ in a UV-spectrophotometer. Real-time quantitative RT-PCR analysis was carried out in a 48-well plate using the Opticon MJ Research instrument (Bio-rad Inc) and optimized standard SYBR Green 2-step qRT-PCR kit protocol $\left(\right.$ DyNAmo $^{\text {ma }}$, Finnzymes, Finland). Specific sense and antisense primers used were as follows respectively: ICAM-1, sense: 5'-GCT GCT ACC ACA CTG ATG ACG ACA A-3, anti-sense: $5^{\prime}$-CAG TGA CCA TCT ACA GCT TTC CGG-3'; MCP-1, sense: 5'-GAT CTC AGT GCA GAG GCT CG-3', anti-sense: $5^{\prime}$-TGC TTG TCC AGG TGG TCC AT-3' [20]; type IV collagen, sense: 5'-GGT GTT GCA GGA GTG CCA G-3', anti-sense: 5'-GCA AGT CGA AAT AAA ACT CAC CAG-3'; CTGF, sense: 5'-GCA AAT AGC CTG TCA ATC TC-3', anti-sense: 5'-TCC ATA AAA ATC TGG CTT GT-3'; TGF- $\beta 1$, sense: 5'-CAA CAA TTC CTG GCG TTA CCT TGG-3', anti-sense: 5'-GAA AGC CCT GTA TTC CGT CTC CTT-3' [21]; GAPDH, sense: 5'-CGA GAA TGG GAA GCT TGT CAT C-3', anti-sense: 5'-CGG CCT CAC CCC ATT TG-3'. The PCR was started at $95^{\circ} \mathrm{C}$ for 15 minutes (hot start) to activate the AmpliTaq polymerase, followed by a 45 -cycle amplification (Denaturation at $94^{\circ} \mathrm{C}$ for 20 seconds, annealing at $60^{\circ} \mathrm{C}$ for 30 seconds, extension at $72^{\circ} \mathrm{C}$ for 60 seconds, and plate reading at $60^{\circ} \mathrm{C}$ for 10 seconds). The temperature of PCR products was elevated from $65^{\circ} \mathrm{C}$ to $95^{\circ} \mathrm{C}$ at a rate of $0.2^{\circ} \mathrm{C} / 1 \mathrm{sec}$, and the resulting data were analyzed by using the software provided by the manufacturer.

\section{Gelatin zymography}

MMP-2 and MMP-9 enzymatic activities were assayed by gelatin zymography [22]. Samples were electrophoresed on $1 \mathrm{mg} / \mathrm{ml}$ gelatin containing 10\% SDS-polyacrylamide gel. After electrophoresis, the gel was washed twice with washing buffer (50 mM Tris- $\mathrm{HCl}, \mathrm{pH} 7.5,100 \mathrm{mM} \mathrm{NaCl}$, $2.5 \%$ Triton $\mathrm{X}-100$ ), followed by a brief rinsing in washing buffer without Triton X-100. The gel was incubated with incubation buffer $(50 \mathrm{mM}$ Tris- $\mathrm{HCl}, \mathrm{pH} 7.5,150 \mathrm{mM}$ 
$\left.\mathrm{NaCl}, 10 \mathrm{mM} \mathrm{CaCl} 2,0.02 \% \mathrm{NaN}_{3}, 1 \mu \mathrm{M} \mathrm{ZnCl}_{2}\right)$ at $37^{\circ} \mathrm{C}$. After incubation, the gel was stained with Commassie brilliant blue R-250 and destained. A clear zone of gelatin digestion was represented with the MMP activity.

\section{Transient transfection and luciferase reporter assay}

Mesangial cells were grown to $60-80 \%$ confluence, and the cells were transiently co-transfected with the plasmids using Lipofectamine LTX (Invitrogen, Carlsbad, CA) according to the manufacture's protocol. Briefly, plasmids linked to a luciferase reporter (MMP-2 promoter) were kindly provided from Lee ST, Yonsei University, Seoul, Republic of Korea. Cells were transiently transfected with $0.5 \mu \mathrm{g}$ of $\beta$-galactosidase $(\beta$-gal). The transfected mixture containing $0.5 \mu \mathrm{M}$ of either the reporter gene constructs ( $\beta$-gal) was mixed with the Lipofectamine LTX reagent and added to the cells. After $24 \mathrm{~h}$, the cells were treated with Oryeongsan for $30 \mathrm{~min}$ and stimulated with $25 \mathrm{mM}$ glucose for $24 \mathrm{~h}$ and then lysed. The luciferase and $\beta$-gal activities were determined as described elsewhere using luciferase assay kit (Promega, Madison, WI). The luciferase activities were normalized with respect to the $\beta$-gal activity.

\section{Preparation of cytoplasmic and nuclear extracts}

The cells were rapidly harvested by sedimentation and nuclear and cytoplasmic extracts were prepared on ice as previously described by the method [23]. Cells were harvested and washed with $1 \mathrm{ml}$ buffer A $(10 \mathrm{mM}$ HEPES, pH 7.9, $1.5 \mathrm{mM} \mathrm{MgCl}_{2}, 19 \mathrm{mM} \mathrm{KCl}$ ) for $5 \mathrm{~min}$ at $600 \times \mathrm{g}$. The cells were then resuspended in buffer $\mathrm{A}$ and $0.1 \% \mathrm{NP} 40$, left for $10 \mathrm{~min}$ on ice to lyse the cells and then centrifuged at $600 \times \mathrm{g}$ for $3 \mathrm{~min}$. The supernatant was saved as cytosolic extract. The nuclear pellet was then washed in $1 \mathrm{ml}$ buffer $\mathrm{A}$ at $4,200 \times \mathrm{g}$ for $3 \mathrm{~min}$, resuspended in $30 \mu \mathrm{l}$ buffer $\mathrm{C}$ (20 mM HEPES, $\mathrm{pH} 7.9$, $25 \%$ glycerol, $0.42 \mathrm{M} \mathrm{NaCl}, 1.5 \mathrm{mM} \mathrm{MgCl} 2,0.2 \mathrm{mM}$ EDTA), rotated for $30 \mathrm{~min}$ at $4^{\circ} \mathrm{C}$, then centrifuged at $14,300 \times \mathrm{g}$ for $20 \mathrm{~min}$. The supernatant was used as nucleus extract.

\section{Immunofluorescence microscopy}

Rat mesangial cells on glass coverslips were fixed in $4 \%$ paraformaldehyde for 30 minutes and then permeabilized with $0.4 \%$ Triton X-100 for 5 minutes in PBS, washed 3 times with PBS. After blocking in 1\% BSA, samples were incubated with primary antibody (p-Smad-2, and Smad-4) at $4^{\circ} \mathrm{C}$ overnight. Corresponding secondary antibodies were labeled with Alexa Fluor 488 (1:200; Molecular Probes, Eugene, OR). Rat mesangial cells nuclei were counterstained with DAPI. Recording and analysis of fluorescence signals were performed using ImagePro software 5.0 (Media Cybernetics, Inc., MD).

\section{Statistical analysis}

All the experiments were repeated at least three times. The results were expressed as a mean \pm S.E., and the data were analyzed using one-way ANOVA followed by Student's $t$-test to determine any significant differences. $\mathrm{P}<0.05$ was considered as statistically significant.

\section{Results}

\section{Effect of Oryeongsan on HG-induced mesangial cell} proliferation

In the $\left[{ }^{3} \mathrm{H}\right]$-thymidine incorporation assay (Figure $1 \mathrm{~A}$ ), stimulation with HG $(25 \mathrm{mM})$ increased cell proliferation. Oryeongsan $(1-50 \mu \mathrm{g} / \mathrm{ml})$ inhibited HG-induced cell proliferation in a dose-dependent manner. HG-induced increase of cell number also reduced by pretreatment of Oryeongsan (Figure 1B).

\section{Effect of Oryeongsan on HG-induced mesangial fibrosis}

This study evaluated whether HG stimulated mesangial cell fibrogenesis and whether Oryeongsan reversed it. Mesangial matrix accumulation was shown to be responsible for renal fibrosis [24]. To investigate inhibitory effects of Oryeongsan on HG-instigated mesangial matrix expansion, production of collagen IV and CTGF was examined. HG-elevated fibrogenic collagen IV protein expressions, was attenuated by adding $\geq 10 \mu \mathrm{g} / \mathrm{ml}$ Oryeongsan. In addition, HG-augmented production of CTGF was suppressed in Oryeongsan-treated rat mesangial cell (Figure 2A). The realtime RT-PCR analysis were employed to confirm that Oryeongsan regulate HG-triggered induction of mesangial type IV collagen and CTGF at transcriptional levels. As shown in Figure 2B, the mRNA expression of type IV collagen and CTGF were markedly reduced by Oryeongsan in HG-exposed cells. Collagen IV secretion encumbered by Oryeongsan was most likely attributed to decreased CTGF production due to its supplementation. Of interest, SB431542, a TGF-beta type I receptor inhibitor, inhibited collagen IV and CTGF levels under high glucose condition. Thus, these results suggest that Oryeongsan improved HG stimulated mesangial cell fibrogenesis, and TGF- $\beta$ signal play a part in HG-induced collagen IV and CTGF expression.

\section{Effect of Oryeongsan on MMP dysfunction initiated by HG}

MT-1 MMP is known to activate pro-MMP-2 to its active form, thereby degrading ECM [25]. Expression of MT-1 MMP and TIMP-2 in HG-treated mesangial cell was assessed using Western blot analysis. Treatment of Oryeongsan was increased on HG-reduced MT-1 MMP expression. Whereas, TIMP-2 expression was augmented in cells exposed to HG, and decreased by Oryeongsan (Figure 3A). Similar to pretreatment of Oryeongsan, SB431542 was increased MT1-MMP protein expression compared with HG alone. The ECM-degrading activity 
A

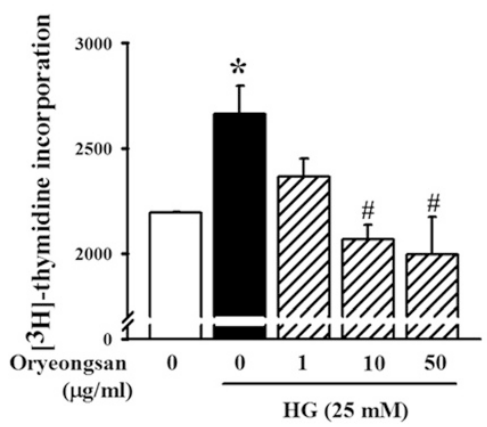

B

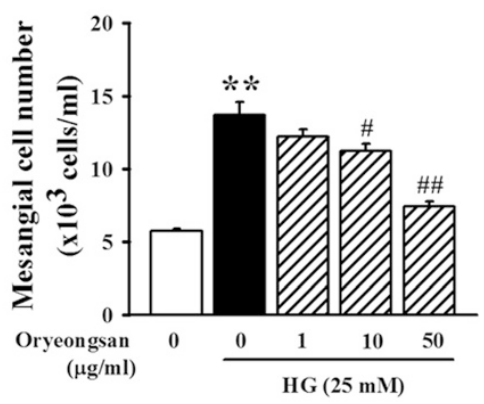

Figure 1 Effects of Oryeongsan on rat mesangial cell proliferation. (A) Mesangial cells were seeded into the 24-well plates. After confluence, the cells incubated for $24 \mathrm{~h}$ with or without $\mathrm{HG}$ and various concentrations of Oryeongsan, and then pulse-labeled with [ $\left.{ }^{3} \mathrm{H}\right]$-thymidine for $24 \mathrm{~h}$. (B) Inhibitory effect of Oryeongsan on proliferation of mesangial cells. Cells were incubated with indicated concentrations of ORS (from 0, 1, 10, and $50 \mu \mathrm{g} / \mathrm{mL}$ ) with or without HG (25 mM) for $24 \mathrm{~h}$. The proliferation inhibition was determined by used Countess ${ }^{\mathrm{TM}}$ cell counting. Results are expressed as the mean \pm S.E. from five independent experiments. ${ }^{*} p<0.05$ vs. control; \#p $<0.05$ vs. HG alone.

of MMP-2 was examined by using gelatin zymography assay. HG suppressed conversion of proMMP-2 to its active form. However, Oryeongsan substantially enhanced gelatinolytic MMP-2 activity diminished by HG (Figure 3B). In addition, Oryeongsan enhanced MMP-2 promotor activity diminished by HG (Figure 3C). Accordingly, compelling evidence was drawn from this study that Oryeongsan had the potential capability to block HG-induced glomerulosclerosis and renal fibrosis.

\section{Interruption of HG-induced TGF- $\beta /$ smad signal pathway} by Oryeongsan

TGF- $\beta$ has been described to contribute a critical role in causing glomerulosclerosis and renal fibrosis. The signaling pathway activated by TGF- $\beta 1$ involves type I receptor-mediated phosphorylation of Smad-2 and Smad-3, thereby allowing them to associate with Smad-4 and to translocate into the nucleus for gene expression [26]. HG enhanced cellular levels of TGF- $\beta$, phospho-Smad-2
A
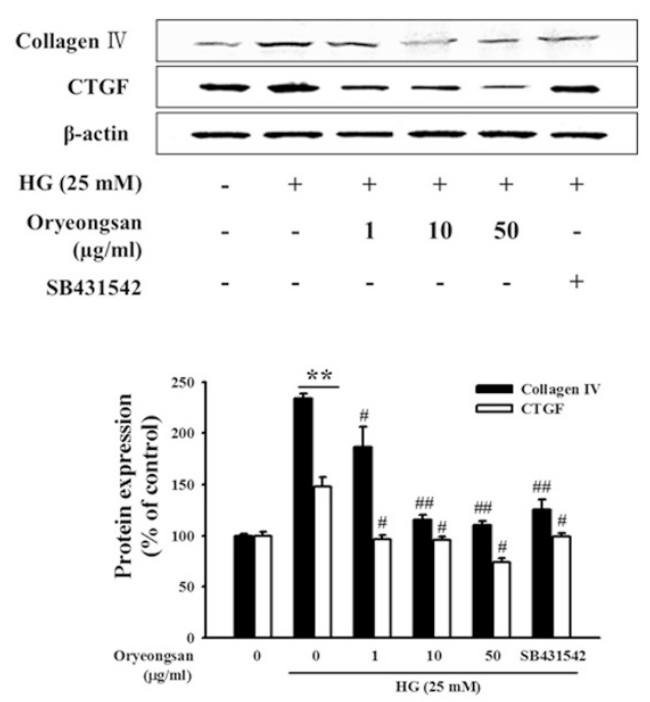

B
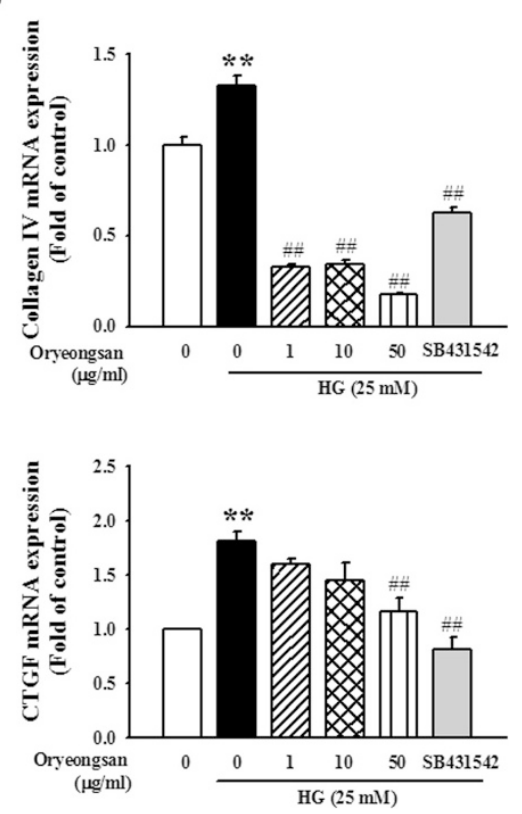

Figure 2 Effect of Oryeongsan on HG-induced type IV collagen and CTGF level. Cell lysates were used for Western blot analysis with a primary antibody against type IV collagen and CTGF. $\beta$-actin protein was used as an internal control. (A) Western blotting and (B) real-time PCR showed protein and mRNA levels of type IV collagen and CTGF in Oryeongsan-treated and HG-stimulated rat mesangial cells. Each value represents the means \pm S.E. of five independent experiments. ${ }^{* *} p<0.01$ vs. control; $\# p<0.05$, \#\#p $<0.01$ vs. HG alone. 


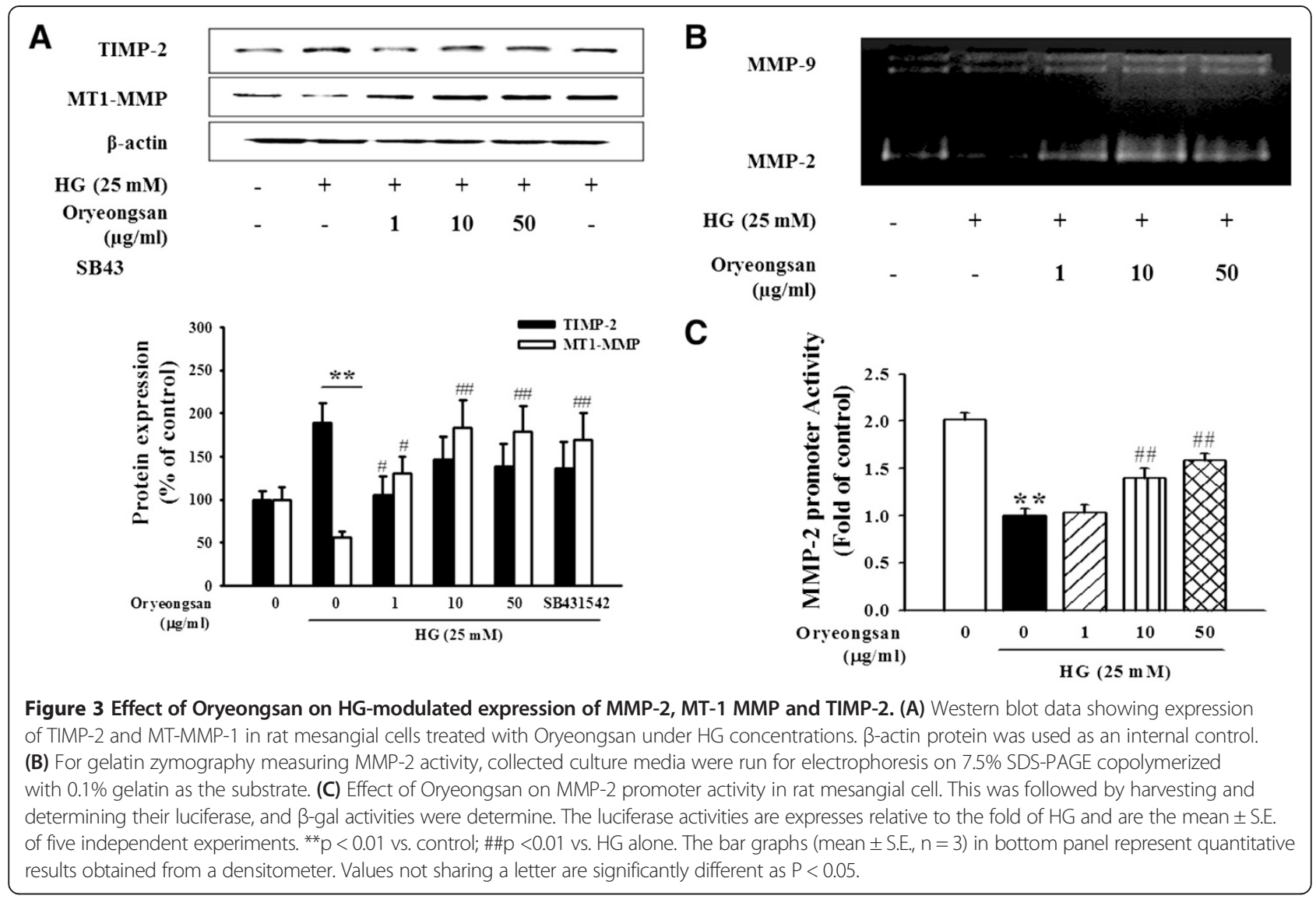

and Smad-4 at $24 \mathrm{~h}$ after stimulation (Figure $4 \mathrm{~A}$ ). When mesangial cell was treated with Oryeongsan, Oryeongsan was decreased TGF- $\beta 1$ expression and Smad- 2 phosphorylation (Figure 4A). Whereas, Smad-7 (I-Smad) expression increased by Oryeongsan under HG condition. In addition, Oryeongsan was reduced HG-induced TGF- $\beta 1$ mRNA expression (Figure 4B). As shown in Figure $5 \mathrm{~A}$ and $\mathrm{B}, \mathrm{p}-$ Smad- 2 could bind to Smad-4 and was translocated into the nucleus in $\mathrm{HG}$ condition. Staining intensities of $\mathrm{p}$ Smad-2/Smad-4 of the HG condition highly increased and p-Smad-2/Smad-4 expression levels in nuclear extracts markedly decreased when treated Oryeongsan. TGF- $\beta$ acts through the Smad pathway involving receptor-regulated Smad-2 and common-mediated Smad-4 [27]. Thus, disturbing Smad-2 phosphorylation or Smad-4 expression may be an approach that will terminate TGF- $\beta$ signaling, thereby blocking TGF- $\beta$-mediated fibrosis. Furthermore, as shown in Figures 4 and 5, Oryeongsan down regulated TGF- $\beta$ and Smads level in the same league as TGF- $\beta$ type I receptor inhibitor SB431542.

\section{Attenuation of inflammatory ICAM-1 and MCP-1 by Oryeongsan in HG-stimulated mesangial cell}

This study elucidated that Oryeongsan may alleviate mesangial inflammation possibly involved in renal fibrotic process. ICAM-1, an important adhesion molecule related to vascular inflammation, promotes inflammatory cells including mononuclear macrophage infiltration into glomeruli and renal interstitium and accelerates glomerular sclerosis in diabetes [28]. This study elucidated that Oryeongsan may alleviate mesangial inflammation possibly involved in renal fibrotic process. HG enhanced ICAM-1 protein expression (Figure 6A). In addition, ICAM-1 and MCP-1 mRNA level also were enhanced in HG-exposed mesangial cells, evidenced by real-time PCR (Figure 6B). This elevation was markedly attenuated by treated by $50 \mu \mathrm{g} / \mathrm{ml}$ Oryeongsan and SB431542, TGF- $\beta$ type I receptor inhibitor. This implies that TGF- $\beta$ was an upstream regulator of pro-inflammatory ICAM-1 and MCP-1. It seems to be plausible that there was a crosstalk between mesangial fibrosis and inflammation that was disrupted by Oryeongsan. It seems to be plausible that there was a crosstalk between mesangial fibrosis and inflammation that was disrupted by Oryeongsan.

\section{Blockade of NF-KB activity by Oryeongsan}

$\mathrm{NF}-\mathrm{kB}$ is activated, it translocates into the nucleus and binds to a specific DNA sequence on target gene promoter to trigger the transcription of target genes related to inflammatory injury [29], which promote 
A
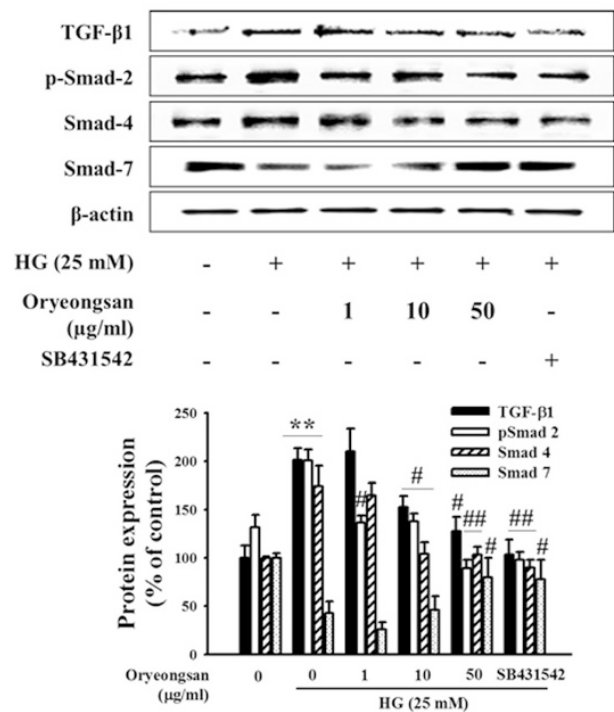

B

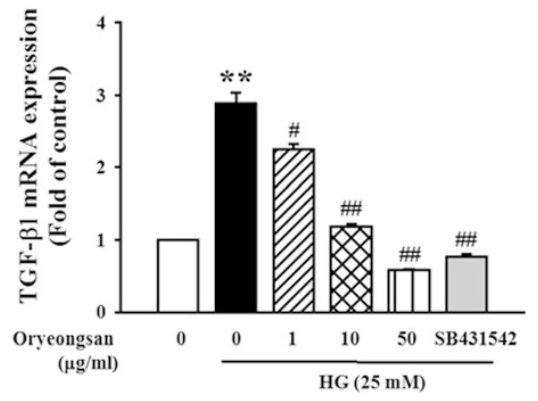

Figure 4 Effect of Oryeongsan on the relative levels of TGF- $\beta 1$ and Smads. (A) The protein bands detected by western blotting, $\beta$-actin was used as the internal standard in each sample. (B) real-time PCR showing mRNA levels of TGF- $\beta$ in Oryeongsan-treated and HG-stimulated rat mesangial cells. Each value represents the means \pm S.E. of five independent experiments. ${ }^{* *} p<0.01$ vs. control; \#p $<0.05, \# \# p<0.01$ vs. HG alone.



Figure 5 Effects of Oryeongsan on translocation of p-Smad-2 (A) and Smad-4 (B) into the cell nucleus in rat mesangial cells.

Immunofluorescent images of p-Smad-2 (A) and Smad-4 (B) nuclear translocation (red arrow) under the laser scanning confocal microscopy were show (magnification. 400X). Nuclei were stained with DAPI (blue) and p-smad-2 (A) and Smad-4 (B) were stained with Alexa Fluor 488 (green). Green fluorescence indicates localization of p-Smad-2/Smad-4. Respective data were obtained from five independent experiments. 
A


B
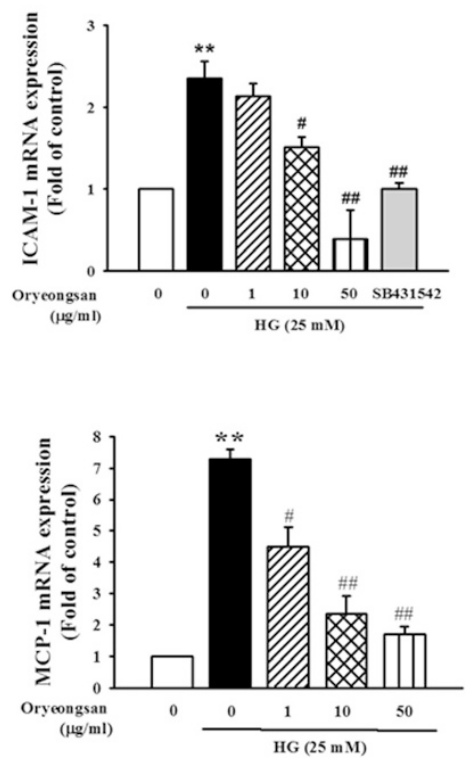

Figure 6 Effect of Oryeongsan-induced inflammatory ICAM-1 and MCP-1. (A) Cell lysates were used for Western blot analysis with a primary antibody against ICAM-1. $\beta$-actin protein was used as an internal control. (B) real-time PCR showing mRNA levels of ICAM-1 and MCP-1 in Oryeongsan-treated and HG-stimulated rat mesangial cells. Each value represents the means \pm S.E. of five independent experiments. ${ }^{* *} p<0.01$ vs. control; \#p <0.05, \#\#p<0.01 vs. HG alone.

mesangial cells proliferation and mononuclear macrophage infiltration and eventually accelerate glomerularsclerosis in diabetic kidney. In Western analysis, HG caused NF-kB p65 translocation in the nucleus, which is inhibited by pretreatment with Oryeongsan. In addition, HG-induced phosphorylation of IkB- $\alpha$, the inhibitors of NF-kB activity, was reduced by Oryeongsan in the cytoplasm (Figure 7).

\section{Discussion}

In the current study, we showed an inhibitory effect of Oryeongsan on HG-induced rat mesangial cell fibrogenesis and inflammation. We demonstrated that Oryeongsan retarded HG-induced mesangial cell fibrogenesis through disturbing TGF- $\beta /$ Smad signaling. Oryeongsan suppressed HG-induced hyperplasia and ECM expansion by improving matrix-degrading MMP system involving TIMP-2. The HG-stimulated CTGF and type IV collagen induction entailed TGF- $\beta$-Smad-responsive pathways that were encumbered by Oryeongsan. Finally, Oryeongsan attenuated inflammatory ICAM-1 and MCP-1 expression in the mesangium.

Diabetic nephropathy, a progressive kidney disease caused by angiopathy of capillaries in the kidney glomeruli, is one of the most severe complications of type I and type II diabetes [30]. The earliest detectable change in the course of diabetic nephropathy is an expansion of the glomerular mesangium, which is caused by excessive accumulation of ECM proteins [31].




Glomerular mesangial cells, an important member of renal glomerulus, play a major role not only in physiological functions but also in pathogenesis of kidney diseases [32]. Mesangial cells comprise approximately one third of decapsulated glomerular cell population with endothelial cells and glomerular visceral epithelial cells comprising the rest. Mesangial cells maintain the structural architecture of the glomerular capillary similar to the function of certain microvascular pericytes. These cells also contribute to mesangial matrix homeostasis, regulate filtration surface area and phagocytose apoptotic cells or immune-complexes formed at or delivered to the glomerular capillaries. Knowledge regarding biological responses of mesangial cells and mesangial matrix in disease states is derived from careful morphological and morphometric evaluation of human kidney biopsies and kidney tissue harvested from experimental models. As such, cell hypertrophy and proliferation as well as matrix expansion were identified as few of the common biological responses of mesangial cell to injury.

CTGF are expressed in the mesangium and play an important role in the ECM-synthesizing process, while MMP is involved in inducing the enzymatic breakdown of ECM [33]. Thus, in renal diseases, targeting CTGF and MMP is considered to resolve or prevent glomerulosclerosis and interstitial fibrosis. This study evaluated whether Oryeongsan modulate HG-induced production of type IV collagen and expression of CTGF. Western blot data showed that Oryeongsan inhibited the type IV collagen and CTGF protein expression enhanced by HG. In addition, Oryeongsan improved the HG-triggered MMP system dysfunction by enhancing ECM-degrading MT-1 MMP expression and repealing TIMP-2 expression. Accordingly, compelling evidence was drawn from this study that Oryeongsan had the potential capability to block HG-induced glomerulosclerosis and renal fibrosis.

Mesangial ECM components not only provide structural support of the glomerular capillary tuft, but also play a more active role by affecting adhesion, migration and proliferation. Activation of the TGF- $\beta 1$ loop leads to cell cycle arrest and ECM synthesis [34]. In mesangial cells, TGF- $\beta 1$ inhibits growth and stimulates the synthesis of collagens, fibronectin, laminin and proteoglycans [35]. The Smads proteins following TGF- $\beta 1$ are thought to be some of the most important factors in the process of ECM accumulation. Thereby, induction and activation of the TGF- $\beta$ / Smad signaling cascade is critical for the initiation of fibrogenic cell responses. TGF- $\beta$-Smad signaling has been reported to play a vital role in the process of ECM expansion. Smad-3 and Smad-4 but not Smad-2 was required for TGF- $\beta 1$-induced CTGF promoter activity and expression in osteoblasts [11]. In this study, we found that Oryeongsan disturbed the TGF- $\beta$-Smad signal pathway through retarding TGF- $\beta$ expression in mesangial cells cultured by HG and downstream activation of Smad-2 and Smad-4 and enhancing the level of inhibitory Smad-7. It is shown in the present study, Oryeongsan decrease TGF- $\beta 1$ and p-Smad-2/Smad-4, and increase Smad-7 expression in mesangial cells cultured by HG. In addition, p-Smad-2/Smad-4 of the HG condition highly increased and $\mathrm{p}$-Smad-2/Smad-4 expression levels in nuclear extracts markedly decreased when treated Oryeongsan. These results suggest that Oryeongsan prevents renal fibrosis process by inhibition of TGF- $\beta / \mathrm{Smad}$ signaling cascade in diabetic nephropathy.

In diabetic patients with nephropathy, the levels of ICAM-1 and MCP-1 recruiting inflammatory immune cells of macrophages and granulocytes were elevated [14]. It was shown that MCP-1 appeared to be responsible for diabetic ECM accumulation and early inflammation in diabetic nephropathy pathogenesis [36]. HG enhanced ICAM-1 protein expression, whereas Oryeongsan reduced that. In addition, ICAM-1 and MCP-1 mRNA level also were enhanced in HG-exposed mesangial cells. This elevation was markedly attenuated by treated with $50 \mu \mathrm{g} / \mathrm{ml}$ Oryeongsan. This study elucidated that Oryeongsan may alleviate mesangial inflammation possibly involved in renal fibrotic process, further diabetic nephropathy.

There is accumulating evidence demonstrating that the diabetic nephropathy is closely related to mesangial inflammation [14]. The activation of NF- $k B$ may play a pivotal role in the progression of renal injury by inflammatory factors in diabetes [37]. Therefore, inhibition of the NF- $k B$ pathway may represent a new therapeutic target for diabetic nephropathy treatment. Normally, NF-kB is retained in the cytoplasm by binding to an inhibitor protein, IкB. Upon stimulation, I $\mathrm{B}$ B is phosphorylated and degraded, and separated from NF- $\mathrm{B}$. Then the activated NF- $k \mathrm{~B}$ is translocated into the nucleus to active transcriptional expression of downstream genes associated with inflammatory responses [38]. This study revealed that HG caused NF-kB p65 translocation in the nucleus, which is inhibited by pretreatment with Oryeongsan. In addition, phosphorylation of I $\mathrm{KB}-\alpha$, the inhibitors of NF- $\kappa \mathrm{B}$ activity, by kinases results in the degradation of $I \kappa B-\alpha$ with release of NF- $\mathrm{kB}$, which translocates to the nucleus where it is active in the regulation of transcription gene. Here we could not rule out the possibility that anti-oxidant activity of Oryeongsan would be involved in beneficial effect of HG-induced renal fibrosis and inflammation, because ROS/ $\mathrm{NF}-\mathrm{kB}$ pathway is critical for those actions. In previous report, it is supported by that Poria cocos, antioxidant, inhibits HG-induced mesangial proliferation [39]. Thus next study is required to clarify the involvement of oxidative stress and anti-oxidant property of Oryeongsan in renal fibrosis using various renal cells and diabetic animal models. 


\section{Conclusion}

Oryeongsan retarded diabetes-associated renal fibrosis and mesangial inflammation through disturbing TGF- $\beta$ / Smad signaling. Oryeongsan suppressed HG-inflamed hyperplasia and ECM expansion by improving matrixdegrading MMP system involving TIMP-2. The HGstimulated CTGF and type IV collagen induction entailed TGF- $\beta$-Smad-responsive pathways that were encumbered by Oryeongsan. Furthermore, Oryeongsan attenuated inflammatory ICAM-1 expression and MCP-1 production in the mesangial cells under HG.

Taken together, these data provide the first evidence that Oryeongsan may play an important role in the prevention of renal fibrosis, inflammation and further glomerulosclerosis. Thus, Oryeongsan may provide new insights into the development of therapeutic drugs for diabetic nephropathy.

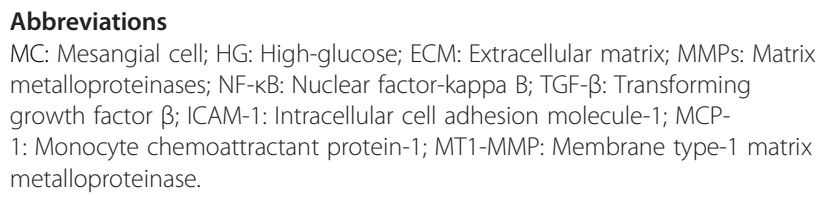

MC: Mesangial cell; HG: High-glucose; ECM: Extracellular matrix; MMPs: Matrix metalloproteinases; NF-kB: Nuclear factor-kappa B; TGF- $\beta$ : Transforming growth factor $\beta$; ICAM-1: Intracellular cell adhesion molecule-1; MCP1: Monocyte chemoattractant protein-1; MT1-MMP: Membrane type-1 matrix metalloproteinase.

\section{Competing interests}

The authors declare that they have no competing interests.

\section{Authors' contributions}

YJJ designed research and wrote the paper; LYJ and LSM conducted research and analyzed data; KDG and LHS had the primary responsibility for final content. All authors read and approved the final manuscript.

\section{Acknowledgements}

This work was supported by the National Research Foundation of Korea (NRF) Grant funded by the Korean government (MSIP) (2008-0062484).

\section{Author details}

${ }^{1}$ Professional Graduate School of Oriental Medicine and College of Oriental Medicine, Wonkwang University, Shinyong-dong, Iksan, Jeonbuk 570-749, Republic of Korea. ${ }^{2}$ Hanbang Body-fluid Research Center, Wonkwang University, Shinyong-dong, Iksan, Jeonbuk 570-749, Republic of Korea. ${ }^{3}$ Brain Korea (BK) 21 plus team, Professional Graduate School of Oriental Medicine, Wonkwang University, Iksan, Jeonbuk 540-749, Republic of Korea.

Received: 3 July 2014 Accepted: 23 January 2015

Published online: 22 February 2015

\section{References}

1. Jia H, Qi X, Fang S, Jin Y, Han X, Wang Y, et al. Carnosine inhibits high glucose-induced mesangial cell proliferation through mediating cell cycle progression. Regul Pept. 2009;154:69-76.

2. Harding P, Balasubramanian L, Swegan J, Stevens A, Glass 2nd WF. Transforming growth factor beta regulates cyclooxygenase-2 in glomerular mesangial cells. Kidney Int. 2006;69:1578-85.

3. Kanwar YS, Wada J, Sun L, Xie P, Wallner El, Chen S. Diabetic nephropathy: mechanisms of renal disease progression. Exp Biol Med. 2008;233:4-11.

4. Abrass CK, Peterson CV, Raugi GJ. Phenotypic expression of collagen types in mesangial matrix of diabetic and non-diabetic rats. Diabetes. 1988:37:1695-702.

5. Adler S. Structure-function relationships associated with extracellular matrix alternationsin diabetic glomerulopathy. J Am Soc Nephrol. 1994;5:1165-72.

6. McLennan SV, Fisher EJ, Yue DK, Turtle JR. High glucose concentration causes a decrease in mesangium degradation. A factor in the pathogenesis of diabetic nephropathy. Diabetes. 1994;43:1041-5.
7. McLennan SV, Wang XY, Moreno V, Yue DK, Twigg SM. Connective tissue growth factor mediates high glucose effects on matrix degradation through tissue inhibitor of matrix metalloproteinase type 1: Implications for diabetic nephropathy. Endocrinology. 2004;145:5646-55.

8. Sharma K, Ziyadeh FN. Hyperglycemia and diabetic kidney disease. The case for transforming growth factor-beta as a key mediator. Diabetes. 1995;44:1139-46.

9. Han DC, Isono M, Hoffman BB, Ziyadeh FN. High glucose stimulates proliferation and collagen type I synthesis in renal cortical fibroblast: mediation by autocrine activation of TGF-beta. J Am Soc Nephrol. 1999;10:1891-9.

10. Petersen M, Thorikay M, Deckers M, van Dinther M, Grygielko ET, Gellibert F, et al. Oral administration of GW788388, an inhibitor of TGF-beta type I and II receptor kinases, decreases renal fibrosis. Kidney Int. 2008;73:705-15.

11. Piek $\mathrm{E}$, Heldin $\mathrm{CH}$, ten Dijke P. Specificity, diversity, and regulation in TGF-beta superfamily signaling. FASEB J. 1999;13:2105-17.

12. Shi Y, Massagué J. Mechanisms of TGF-beta Signaling from Cell Membrane to the Nucleus. Cell. 2003;113:685.

13. Tuttle KR. Linking metabolismand immunology: diabetic nephropathy is an inflammatory disease. J Am Soc Nephrol. 2005;16:1537-8.

14. Fornoni A, ljaz A, Tejada T, Lenz O. Role of inflammation in diabetic nephropathy. Curr Diabetes Rev. 2008;4:10-7.

15. Chow FY, Nikolic-Paterson DJ, Atkins RC, Tesch GH. Macrophages in streptozotocin-induced diabetic nephropathy: potential role in renal fibrosis. Nephrol Dial Transplant. 2004;19:2987-96.

16. Bondar IA, Klimontov W, Nadeev AP. Urinary excretion of proinflamma-tory cytokines and transforming growth factor beta at early stages of diabetic nephropathy. Terapevtichesky Arkhiv. 2008;2008(80):52-6.

17. Liu W, Tang F, Deng Y, Li X, Lan T, Zhang X, et al. Berberine reduces fibronectin and collagen accumulation in rat glomerular mesangial cells cultured under high glucose condition. Mol Cell Biochem. 2009;325:99-105.

18. He L, Rong X, Jiang JM, Liu PQ, Li L. Amelioration of anti-cancer agent adriamycin-induced nephritic syndrome in rats by Wulingsan (Gorei-San), a blended traditional Chinese herbal medicine. Food Chem Toxicol. 2008;46:1452-60

19. Foidart JB, Dechenne CA, Mahieu P, Creutz CE, Mey de J. Tissue culture of normal rat glomeruli.lsolation and morphological characterization of two homogeneous cell lines. Invest Cell Pathol. 1979;2:15-26.

20. Erdèlyi K, Kiss A, Bakondi E, Bai P, Szabó C, Gergely P, et al. Gallotannin inhibits the expression of chemokines and inflammatory cytokines in A549 cells. Mol Pharmacol. 2005;68:895-904.

21. Chung AC, Huang XR, Zhou L, Heuchel R, Lai KN, Lan HY. Disruption of the Smad7 gene promotes renal fibrosis and inflammation in unilateral ureteral obstruction (UUO) in mice. Nephrol Dial Transplant. 2009;24:1443-54.

22. Rhee JW, Lee KW, Sohn WJ, Lee Y, Jeon OH, Kwon HJ, et al. Regulation of matrix metalloproteinase-9 gene expression and cell migration by NF-KB in response to CpG-oligodeoxynucleotides in RAW 264.7 cells. Mol Immunol. 2007:44:1393-400.

23. Dschietzig T, Richter C, Pfannenschmidt G, Bartsch C, Laule M, Baumann G, et al. Dexamethasone inhibits stimulation of pulmonary endothelins by proinflammatory cytokines: possible involvement of a nuclear factor kappa B dependent mechanism. Intensive Care Med. 2001;27:751-6.

24. Li J, Lee YS, Choi JS, Sung HY, Kim JK, Lim SS. Roasted licorice extracts dampen high glucose-induced mesangial hyperplasia and matrix deposition through blocking Akt activation and TGF- $\beta$ signaling. Phytomedicine. 2010;17:800-10.

25. Kang SW, Choi JS, Choi YJ, Bae JY, Li J. Licorice isoliquiritigenin dampens angiogenic activity via inhibition of MAPK-responsive signaling pathways leading to induction of matrix metalloproteinases. J Nutr Biochem. 2010;21:55-65.

26. Parsons CJ, Takashima M, Rippe RA. Molecular mechanisms of hepatic fibrogenesis. J Gastroenterol Hepatol. 2007;22:79-84.

27. Miyazono K, ten Dijke P, Heldin CH. TGF-beta signaling by Smad proteins. Adv Immunol. 2000;75:115-57.

28. Okada S, Shikata K, Matsuda M, Ogawa D, Usui H, Kido Y, et al. Intercellular adhesion molecule-1-deficient mice are resistant against renal injury after induction of diabetes. Diabetes. 2003;52:2586-93.

29. Poljakovic M, Nygren JM, Persson K. Signalling pathways regulating induciblenitricoxidesynthase expressionin humankidney epithelial cells. Eur J Pharmacol. 2003;469:21-8. 
30. Yamagishi S, Fukami K, Ueda S, Okuda S. Molecular mechanisms of diabetic nephropathy and its therapeutic intervention. Curr Drug Targets. 2007:88:952-9.

31. Tang D, He B, Zheng ZG, Wang RS, Gu F, Duan TT, et al. Inhibitory effects of two major isoflavonoids in Radix Astragali on high glucose-induced mesangial cells proliferation and AGEs-induced endothelial cells apoptosis. Planta Med. 2011;77:729-32.

32. Kurogi Y. Mesangial cell proliferation inhibitors for the treatment of proliferative glomerular disease. Med Care Res Rev. 2003:23:15-31.

33. Pozzi A, Voziyan PA, Hudson BG, Zent R. Regulation of matrix synthesis, remodeling and accumulation in glomerulosclerosis. Curr Pharm Des. 2005:15:1318-33.

34. Wolf G. Molecular mechanisms of diabetic mesangial cell hypertrophy: a proliferation of novel factors. J Am Soc Nephrol. 2002:13:2611-3.

35. Schöklmann HO, Lang S, Kralewski M, Hartner A, Ludke A, Sterzel RB. Distinct structural forms of type I collagen modulate cell cycle regulatory proteins in mesangial cells. Kidney Int. 2000;58:1108-20.

36. Chao CY, Mong MC, Chan KC, Yin MC. Anti-glycative and anti-inflammatory effects of caffeic acid and ellagic acid in kidney of diabetic mice. Mol Nutr Food Res. 2010;54:388-95.

37. Schmid H, Boucherot A, Yasuda Y, Henger A, Brunner B, Eichinger F, et al. Modular activation of nuclear factor-kappaB transcriptional programs inhuman diabetic nephropathy. Diabetes. 2006;55:2993-3003.

38. Maziere C, Maziere JC. Activation of transcription fac-tors and gene expression by oxidized low-density lipo-protein. Free Radic Biol Med. 2009:46:127-37.

39. Yoon JJ, Lee YJ, Lee SM, Jin SN, Kang DG, Lee HS. Poria cocos inhibits high glucose-induced proliferation of rat mesangial cells. Am J Chin Med. 2013:41:71-83

\section{Submit your next manuscript to BioMed Central and take full advantage of:}

- Convenient online submission

- Thorough peer review

- No space constraints or color figure charges

- Immediate publication on acceptance

- Inclusion in PubMed, CAS, Scopus and Google Scholar

- Research which is freely available for redistribution 